The Physician and Sports Medicine http://www.physsportsmed.com/issues/2000/09_00/pa_sandor.htm Another American site which is quite good fun. Little emphasis on description, risk factors, prevention and symptoms but has a very elaborate section on different exercises with cartoon pictures on how to improve shoulder motion. Little information is available on the indications for surgery or expected outcome.**

\section{Anterior cruciate ligament injuries and reconstruction}

HM AL-KHATEEB

Luton and Dunstable Hospital, UK

(E: drheshamalkhateeb@msn.com)

Over the past decade, there has been an increase in interest and participation in sports. Concomitant with this, there has been an increase in sports-related injuries, particularly to the lower limbs. Of specifically ligamentous injuries to the knee, rupture of the anterior cruciate ligament (ACL) has been the commonest, and has the greatest potential to cause both short- and long-term disability. The development of surgery for ACL instability has been proceeding over the last century and multiple techniques are available for reconstruction of the ACL. Controversy certainly exists as to which autograft is best and which methods of placement and fixation should be used. What follows is a review of selected internet sites providing up-to-date information for both orthopaedic surgeons and their patients.

\section{www.emedicine.com/pmr/topic3.htm}

This 'emedicine' website offers an excellent resource for the orthopaedic surgeon, giving comprehensive information which is well thought through and referenced. It includes logical subheadings for background, pathophysiology, symptoms and signs, diagnosis and treatment. There is a discussion on the complications as well as the medicolegal pitfalls. It is an excellent site which is both concise and comprehensive. ${ }^{* * * *}$

\section{www.orthoassociates.com/ACL_Page.htm}

The Orthopaedic Associates website is a useful resource for both the patient and surgeon. The site provides information on: (i) knee ligament anatomy; (ii) indications for ACL surgery; (iii) ACL graft choices; (iv) surgical technique using patellar tendon; and (v) rehabilitation protocol. Numerous and excellent illustrations including arthroscopic and diagrammatic pictures. ${ }^{* * *}$

\section{www.arthroscopy.com/sp05018.htm}

This site offers an excellent resource for the orthopaedic surgeon, giving comprehensive technical information. Topics covered include knee joint anatomy and function, diagnosis and treatment, and a demonstration of an ACL reconstruction using the central third of the patella tendon. The site contains impressive arthroscopic pictures depicting a step-by-step ACL reconstruction procedure. ***

\section{www.orthoinfo.org/indepth/}

thr_report.cfm?Thread_ID=14\&topcategory=Knee

This site is provided by the American Academy of Orthopedic Surgeons (AAOS) and provides education and management services for orthopaedic surgeons and health professionals. The section on ACL injury describes the anatomy and pathophysiology of ACL injuries, the surgical and non-surgical options, the operative procedure and the potential operative complications. The site is an excellent source of information and is well laid out and easy to read. ${ }^{* * * *}$

\section{www.anteriorcruciateligament.com/}

\section{index.php?practiceld=3100\&dir=categories\&lib=Injury\&categoryld=187}

This website is created by the Carleton University Sports Medicine Clinic established in 1972 and provides sports medicine education to physicians and patients online. The site is targeted at a patient audience and provides the reader with information about an overview of the common causes of injury using video animation and also discusses the various treatment options available.***

www.wheelessonline.com/ortho/anterior_cruciate_ligament

This site provides a wealth of technical information to the orthopaedic surgeon. Topics covered include the anatomy of the $A C L$, biomechanics of the $A C L$, mechanism of the ACL tear, evaluation of $\mathrm{ACL}$ tears and the surgical management and techniques available. The site contains excellent MRI scans and arthroscopic pictures depicting the various topics covered. ${ }^{* * * *}$

\section{Burn Injuries}

\section{CHRISTOPHER ABELA, GREG WILLIAMS}

Central London Burns Unit, Chelsea and Westminster Hospital, 369 Fulham Road, London, UK (E: DrChrisAbela@hotmail.com)

Burn injuries lend themselves to sensationalism. Many sites exist on the worldwide web but few are clinically orientated and this review focuses on those that we expected to inform surgical trainees and several that achieved where these failed. Useful web-based literature was graded on certain criteria including management rationale, factual information, digital photography and practicalities of site use.

\section{http://www.burnsurgery.org}

This excellent site is aimed at clinicians and covers all topics to a good introductory level. It is especially good at summarising important issues in burn care such as nutrition, antisepsis, wound healing and eventually scar management. Good serial photography and modular format help to impart an overview of the timeline of a patient's care from admission to discharge. The section on 'burn prevention' is specifically good for the education of parents and at risk individuals. ${ }^{* * * *}$

\section{www.britishburnassociation.co.uk}

This British association site offers excellent practical advice on first-aid and prehospital care. It is a must for anyone working in the community and in casualty. National guidelines on 
appropriate referral are summarised succinctly and inform individuals what important information should be imparted in a handover. It possesses a similar format to the American association's website, having links to it and the euroburn.nl, worldburn.com and Australian (anzba.org.au) sites.***

\section{http://www.emedicine.com}

This American website is has been recently updated. By registering for free and searching under 'Burn', numerous relevant articles are found. Some of these are illustrated with colour photographs. A good introduction to the burns' history with a succinct outline of burn assessment and resuscitation are the strengths of the general pages. The articles on facial, electrical and chemical burns deliver more detail on subjects only touched upon in the overview pieces. ${ }^{* *}$

\section{http://www.health.nsw.gov.au/public-health/burns/burnsmgt.pdf} These guidelines for the management of burn injuries were produced by the Australian and New Zealand burn association almost 10 years ago. Although the pictures are in black and white, the PDF makes for a succinct summary of the initial management of small (those that do not need fluid resuscitation) burn injuries in the rural accident and emergency department. It is especially useful for algorithms of wound management, aimed at those clinicians without direct access to burns specialists and advises guidance on referral criteria. It suffers from the usual problems of foreign websites, namely that trademarked treatments in the UK are different.***

\section{www.ameriburn.org}

This is the official site of the American Burn Association. It contains links to courses, conferences and research fellowships with grants. It has limited clinical information but gives an excellent review of the wider context of burn care including prehospital care, the logistical necessaries of setting up a burns unit and advice on access to ancillary staffing and post-hospital continuity of care. It introduces the concepts of a burn registry and details data desirable for audit. **

\section{http://www.phoenix-society.org}

This American support website tackles the psychological issues surrounding burn patients. It identifies difficult areas of rehabilitation and offers advice for patients and relatives on dealing with individuals who stare, problems of self-esteem, repeated hospitalisation, teasing and changes in family dynamics. It also touches upon the sensitive topics of regaining sexuality and the guilt of survival. With downloadable articles, it offers a good source of information for lay people and professionals to work together through anxious times. It is a useful resource when asked by patients or relatives for avenues to source and share experiences. **

\section{www.burnsurvivorsassociation.com}

These pages contain no medical information but plentiful links to survivor support organisations and professional bodies. *

\section{Patient information: hip and knee arthroplasty}

\section{H BOSMAN}

Department of Orthopaedics, Broomfield Hospital, Chelmsford, Essex, UK

\section{Arthritis Research Campaign (ARC)}

\section{www.arc.org.uk}

This British site contains downloads of all ARC's leaflets. This wellestablished organisation provides glossy leaflets for out-patient clinics and GP surgeries. All are available to download in PDF. The information, set out in a standard format, is comprehensive, if at times simplistic. As well as information on arthritis in general, there are tips on exercises, how to do gardening, drugs, physiotherapy and arthroplasty. It is a good place to start and includes information on hip and knee replacement, unicompartmental knee replacement, hip resurfacing and alternatives to surgery. It is the best site for information on operative risk providing reliable, quotable figures for all of the major compilations. The site does not go into the amount of technical detail as demanded by much of the patient group. It lacks any detailed images or interactive content. The ARC could also provide more foreign languages leaflets, at present osteomalacia is the only topic with multilingual attention.***

\section{NHS Direct}

\section{www. besttreatments.co.uk}

Similar to the ARC website but without the breadth of information, NHS Direct outlines the basics of hip and knee replacement, the risks and benefits and what to expect. It is the only site to reference the information provided. It is set out in similar language to ARC, describing hip and knee replacement as a 'big operation'. There is no multilingual content. The site also lacks good diagrams and images. It is useful to re-inforce information but does not offer any additional insight. ***

\section{Edheads}

\section{www.edheads.org}

This excellent American site, sponsored by DePuy and Zimmer, gives patients an opportunity to play at surgeon, with an X-ray quiz and interactive surgery. There are also a series of not too gory theatre photos. It allows patients to get a real understanding of the technical aspects of arhroplasty. There is also 'my story', a video montage of patient experiences (all good ones!). Unfortunately, it is limited to total knee replacement and, being sponsored by a manufacturer, there is no mention of risks and postoperative rehabilitation. The site requires Flash so is not available to all. Overall, it is an excellent site and one I would recommend to any patient who wants to have a real understanding of what their operation will entail. ${ }^{* * * *}$

Total Knee Info www.totalkneeinfo.com

This heavily sponsored site has an overview of total knee and hip arthroplasty. It also has links to other relevant sites. There is 